\title{
NOISE: THE DISEASE OF URBAN ENVIRONMENTS. MANAGEMENT AND PROTECTION MEASURES
}

\author{
Bojan Đerčan ${ }^{A}$, Dajana Bjelajac ${ }^{A}$, Milka Bubalo ŽivkovićA , Dragica GatarićB \\ Received: June 19, 2019 | Accepted: November 25, 2019 \\ DOI: 10.5937/ZbDght1902127D
}

\begin{abstract}
Communal noise is the noise that comes from living together. It is the noise in the interior or exterior, whether in the working or living environment, spaces in public buildings or open public areas. The issue of communal noise has been partially resolved on paper by lows and by-lows on the permissible noise levels in the environment. However, the question is how much noise the community will tolerate, ie, at what point citizens will start fighting noise. Numerous cities have signed strict regulations for reducing noise levels, both day and night, with a proposal for permitted limits. This paper presents commonly used methods for managing and protecting against the harmful effects of noise.
\end{abstract}

Keywords: noise; cities; pollution; environment; management; protection.

\section{INTRODUCTION}

The rapid development and intensive urbanization process have caused a number of problems related to urban life. The environmental problems of the modern world present obstacles both in terms of economic and social progress as well as human development all around the world. Coordination between state environmental institutions and the private sector, including the implementation of many projects and initiatives, should be imperative for the future sustainable development of urban environments (Jaafreh, Nagy, 2018). Protecting the environment encompasses a number of legally determined, different but interrelated values that together represent the conditions for the healthy, safe and effective life of present and future generations. Environmental protection should include the protection of nature and natural resources, the purity of air, water and soil, the conservation of flora and fauna as well as urban values, and the pro-

A University of Novi Sad, Faculty of Sciences, Department of Geography, Tourism and Hotel Management, Trg Dositeja Obradovića 3, Novi Sad, Serbia; contact: bojan.djercan@dgt.uns.ac.rs

B University of Belgrade, Faculty of Geography, Studentski trg 3/III, Belgrade, Serbia. 
tection against pollution of all types of ionizing radiation, harmful noise, vibration etc. (Jovaševic, 2005).

Noise is a specific form of pollution in the modern world. It appeared as a problem at the very beginning of urbanization and urban housing, while as a serious environmental problem, it occurred with the appearance of industry in the late 18th and early 19th centuries (Roth, 2001). The development of modern technology, urbanization, accelerated industrialization, especially the development of the transport and automotive industries, caused the noise problem to become a serious environmental problem in the modern world (Li et al., 2002; Brainard et al., 2004; Li and Tao, 2004; Geurs and Wee, 2006; Allen et al., 2009; Ausejo et al., 2010; Ross et al., 2011).

Noise is a subjectively unpleasant auditory experience, a pervasive adverse factor in the living and work environment, and is one of the physical factors harmful to health. The European Union marks environmental noise as one of Europe's leading environmental problems. According to the World Health Organization, the overall noise level is increasing by one decibel a year, and about 120 million people have hearing problems. In the European Union, about $40 \%$ of the population is exposed to communal noise which intensity is higher than $55 \mathrm{~dB}$ during the day, and more than $30 \%$ of the population is exposed to the same noise level during the night. This noise exposure can cause serious irritation and sleep disturbance. Therefore, noise is one of the leading risk factors which compromises overall health integrity (WHO, 2011; 2012).

In the European Union, this problem is receiving much more attention than in other parts of the world (Gan et al., 2012). According to EC recommendations, all Member States are required to produce strategic noise maps for urban areas with more than 250,000 inhabitants (European Commission, 2002).

The age of industrialization and urbanization in which we live are the basic factors for the multiplication of artificial noise sources. Historically, the beginning of industrialization dates back to 1733, when textiles began to be machine-made. Thus, it designates the beginning of the transition from hand-made products to machine-made ones. In the same period, a population increase was observed:

- In 1650, the Earth's population was 550 million,

- In 1750, the Earth's population was 730 million,

- In 1850, the Earth's population was 1.7 billion,

- In 1950, the Earth's population was 2.5 billion,

- In 2050, the Earth's population is estimated at 10 billion (UN, 2019).

Urbanization is also in expansion. In 1964, there were 91 cities with over a million inhabitants and 200 million people. In the former Yugoslavia, in 1964, there were only 4 cities with over 100,000 inhabitants, and by 1974 the number of cities with over 100,000 inhabitants was 27. According to the 2011 census, about $26 \%$ of the Serbian urban population (excluding Kosovo and Metohija) lived in Belgrade. In more developed urban centers, there has been an excessive concentration of population and economy, which in a way has brought negative consequences in the economic, social, spatial and environmental spheres of these cities (Đerčan et al., 2017). It is clear that in this way, urban are- 
as are becoming major sources of artificial noise and that an increasing number of people living in urban areas are thus endangered.

The automotive industry as a source of urban noise is certainly one of the biggest problems. The onset of automobile industry dates back to 1770 and the first steam car with an explosive engine was produced in 1883. Car production amounted to around 80,000 in 1904, and by 1964 about 150 million cars were in circulation. The most important sources of industrial machinery are: pneumatic drills, cranes, generators, tool rivets, grinders, and household appliances: washing machines and dishes, vacuum cleaners, mixers, radios, turntables, transistors, televisions, stereos, lifts, faulty appliances, sirens. Also, high noise is recorded near bus and train stations, subways, airports, industrial plants, etc. (Poparić, 2011).

The phenomenon of sound waves which cause noise is studied within physics. The branch of physics that studies the appearance and propagation of sound waves is called acoustics. The effects of noise and its harmful effects on humans have been studied within biology and medicine. Technical measures for noise protection and their implementation are included in construction and architecture. Therefore, studying the phenomenon of noise, its impact on humans, planning environmental measures, as well as adopting appropriate legal norms, are jobs that require the participation of natural, medical, technical and social (real) sciences and make this field multidisciplinary. Due to its complexity and multidisciplinarity, this phenomenon requires the integration of knowledge from multiple fields in order to adequately enable environmental planning and protection (Poparić, 2011).

\section{NOISE OBSERVATION}

The human ear is able to recognize both very quiet and very loud sounds, from whispers to the sound of a supersonic aircraft, i.e. from $20 \mathrm{~Hz}$ (low frequency) to $20 \mathrm{kHz}$ (high frequency). The human ear is not equally sensitive to different frequencies. Among the two sounds of equal volume, the deep sound will be perceived as weaker compared to the treble. For this reason, a physiological unit of noise measure was created that takes into account this particular ear sensitivity: decibel or $\mathrm{dB}(\mathrm{A})$.

Thus, when it comes to noise, we are not all equal. Although sound, or noise levels, are expressed in universal units, no sound scale can provide an absolute indication of the interference caused to an individual. Our personal experience of sound and noise is conditioned by our psychophysical state, biological material, cultural environment, but also personal experiences.

Table 1 informatively shows the relationships between the noise level, the type of sound environment we are in, and the effect produced by the audibility (speech recognition). These values are given in the table for illustrative purposes only, since the perception of noise has a strong subjective character and is highly dependent on local or temporal context. 
Table 1. Environmental sounds, appropriate sound levels (decibels), and voice communication capability

\begin{tabular}{|c|l|l|}
\hline Sound level $[\mathrm{dB}(\mathrm{A})]$ & The type of sound environment & Conversation \\
\hline $0-10$ & Audibility threshold - leaf rustle in the wind & Quiet voice \\
\hline 20 & Whisper & \\
\hline 30 & Clock ticking & \\
\hline 40 & Speech & Normal voice \\
\hline 55 & TV & Loud voice \\
\hline 60 & Flat on a busy street, noise in a big office & \\
\hline 70 & Busy street, cafe noise, hair dryer & Difficult \\
\hline 80 & Metro, big crowd, car & Yelling \\
\hline 90 & Truck, a very busy intersection & Impossible conversation \\
\hline 95 & Train & \\
\hline 100 & Electric saw, drill & \\
\hline 105 & Pneumatic hammer & \\
\hline 110 & Loud music & \\
\hline 120 & Rock concert near the speakers, thunder & \\
\hline 130 & Civil defense siren & \\
\hline $130-140$ & Threshold of pain & \\
\hline 140 & The jet plane & \\
\hline 180 & Space shuttle platform & \\
\hline & & \\
\hline
\end{tabular}

Source: Poparić, 2011.

Individual noise sensitivity is a significant factor in assessing the interfering effect of noise. The results of several years of prospective studies show that about $10 \%$ of the population is seriously affected by noise. Particularly sensitive are the children under the age of 6 and people over 65 . Middle-aged women are slightly more sensitive than men. Individual susceptibility is also affected by the state of the neurovegetative and vascular systems, certain viral infections, alcohol use, tobacco, and occupational exposure to neurotoxic substances (Ecological Bulletin, 2004).

In the noisy environment, speech communication is difficult due to the masking effect, since the frequency range from $300 \mathrm{~Hz}$ to $3 \mathrm{kHz}$ is especially important for understanding speech, and the largest part of the communal noise sound energy belongs to this range (Ecological Bulletin, 2004).

Noise decreases with distance from the sound source: when the distance is doubled, the sound level drops by $6 \mathrm{~dB}$. Decibels are not summed arithmetically but by logarithmic progression. Thus, when two sound sources of the same intensity are connected, the sound level increases by three decibels, which for the human ear represents a barely noticeable change. For example, adding two $60 \mathrm{~dB}$ sounds does not produce $120 \mathrm{~dB}$ sound but $63 \mathrm{~dB}$ sound. In other words, if the traffic is halved, the sound environment will be more comfortable by only $3 \mathrm{~dB}$. 
If we quadruple the sound source, where all ten are of equal intensity, the noise level will increase by $10 \mathrm{~dB}$, which corresponds to the feeling of doubled volume. Therefore, car traffic should be reduced ten times in order for the noise level at the observed site to be reduced by $10 \mathrm{~dB}$ (assuming that vehicles are moving at the same speed).

When the difference between the two sound sources is $10 \mathrm{~dB}$, the human ear only recognizes a louder source, which is explained by the so-called sound masking effect.

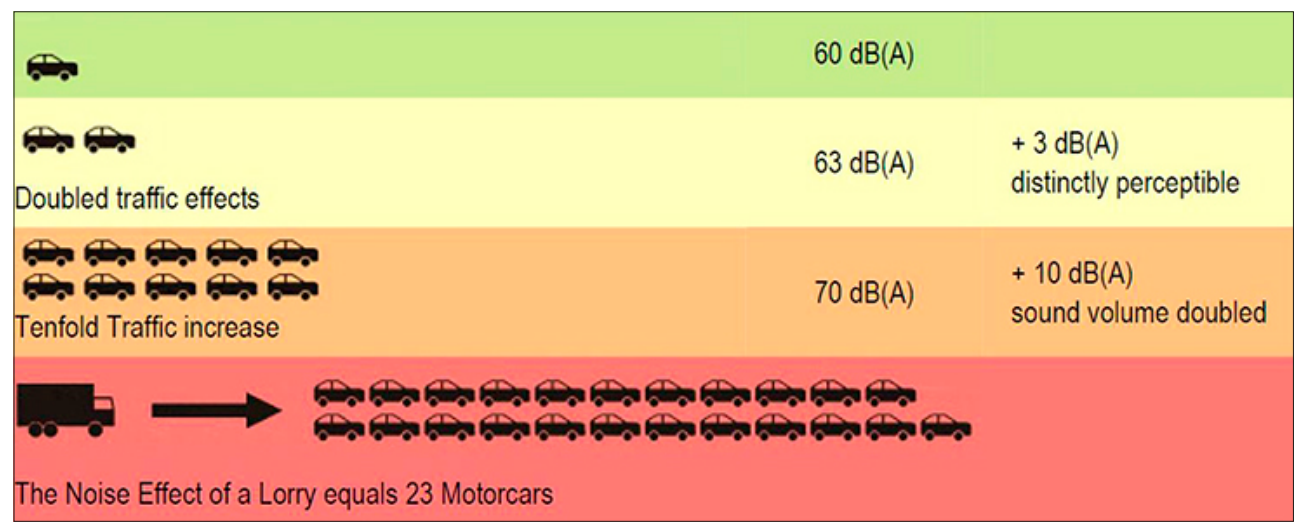

Figure 1. Relationship between traffic volume, truck traffic share and average noise Source: Noise reduction plan for Berlin, 2008.

\section{NOISE IN THE CITY CENTER}

By city noise we mean different types of noise sources that can cause us more or less inconvenience and disturbance: loud music and celebrations, road, air and rail traffic, industry, construction works, night clubs, alarms, dog barking, sports activities, neighborhood noise etc. Therefore, urban noise is recognized as a very important issue in the complex of environmental topics. Noise affects our physiological and psychological state by interfering with basic human activities - sleep, rest, learning, work and communication. Although links between human health and noise have long been observed, only recent research has shown that even the slightest amount of noise, previously considered harmless, can have a very negative impact on human health.

Of the abovementioned noise sources, traffic (urban, air, and railway traffic) has the greatest impact on human beings. As the increasing number of Europeans live in cities (according to the United Nations, in 2011739.3 million people lived on the European continent, $72.9 \%$ of them lived in cities), the volume of traffic is steadily increasing. It is therefore not surprising that national statistics are recording an increasing number of complaints and reports relating to the sound environment.

Noise pollution is no less dangerous than any other pollution. Prolonged exposure to high noise can cause temporary or permanent mental and physical damage to the human body. It can also cause headache, mental stress, insomnia, high blood pressure, cardiac arrhythmia, breathing disorders as well as miscarriages, and decreased concen- 
tration. A survey performed by Work for a Better Bangladesh interviewed over 2,500 people in Bangladesh, of whom 1,000 were students. The results show that $97 \%$ of students are exposed to noise and that $60-70 \%$ of them have problems with concentration, headache and worsening of the general health condition caused by harmful noise effects. Of the other 1500 respondents, $69 \%$ have headaches, $68 \%$ deterioration in health, $49 \%$ deviation from normal body temperature, $42 \%$ have hearing problems, $42 \%$ have arrhythmia and 39\% suffer from insomnia (Đerčan, 2019).

Industrial workers in London are exposed to noise with a volume equal to that which causes deafness. Hearing in young people may be impaired by spending long time in nightclubs. According to some estimates, in Europe, $40 \%$ of the population is exposed to traffic noise intensities above $55 \mathrm{~dB}$ (A) during the day, and as much as $20 \%$ are exposed to noise levels higher than $65 \mathrm{~dB}(\mathrm{~A})$. These noise levels are considered unacceptable for long-term population exposure. When analyzing human exposure to noise at work, the data is poor not only in underdeveloped but also in economically developed countries. In the US, about $30 \%$ of the working population is exposed to noise at work above $85 \mathrm{~dB}(\mathrm{~A})$, and $20 \%$ of the population is exposed to the noise above $90 \mathrm{~dB}(\mathrm{~A})$. Exposure to noise over $90 \mathrm{~dB}(\mathrm{~A})$ during whole work experience is estimated to cause permanent hearing impairment in 25\% of those exposed. In the European Union, 30\% of workers spend more than a quarter of their time working in health-threatening noise, and it is not surprising that $7 \%$ of the working population have impaired hearing, and a high 30\% have a recognized hearing loss due to excessive noise at work, as an occupational disease (Kristoforović -Ilić et al., 1998; Belojević et al., 2011; Đerčan et al., 2015).

\section{NOISE MANAGEMENT}

\section{Noise management legislation}

At EU level, noise protection has a long tradition, and efforts that have been made in this area of protection for years have resulted in Directive 2002/49/EU, which regulates noise management along with other laws. Part of the European Union's policy is to achieve a high level of health and environmental protection, and one of the goals to be pursued is noise protection. In Future Noise Policy. European Commission Green Paper, the Commission addressed communal noise as one of the biggest environmental problems in Europe. In its Resolution, adopted on June 10, 1997 on the Commission's Green Paper, the European Parliament expressed its support for that Green Paper and called for the identification of specific measures and initiatives by the Municipal Noise Reduction Directive, and noted the lack of reliable and comparable data on the state of the various noise sources. A common noise indicator and a common methodology for the calculation of noise and measurement near airports are defined in the Commission Communication of 1 December 1999 on air transport and the environment (Đerčan, 2019).

This Directive should create the basis for the development and completion of existing European Union noise reduction measures produced by major sources, in particu- 
lar road and rail vehicles and infrastructure, aircrafts, industrial equipment and mobile machinery, and for the introduction of additional short, medium and long-term measures. Data on communal noise levels should therefore be collected, sorted and published according to comparable criteria. This involves the use of harmonized indicators and methods of determination, as well as criteria for harmonizing the production of noise maps. Such benchmarks and methods are best identified at European Union level. The Directive requires compliance with indicators and thresholds, mapping and drawing up action plans and proposes regular evaluation of this Directive (European Commission, 2002).

A number of laws in our country treat an environmental issue as a whole or they treat particular aspects of it, such as: food, water, air, soil, etc. In doing so, an attempt was made in order to create a solid legal basis of legal and by-law character that would create obligations for all subjects of social life in their daily life and work, i.e. the basis of responsibility and punishment in case of violation of these regulations (Jovaševic, 2005).

The basic framework for noise management in the urban environment in the Republic of Serbia is laid down by the Law on Protection against Environmental Noise ("RS Official Gazette", No. 36/2009, 88/2010). This legal act defines issues of importance for environmental protection and human health, such as environmental entities, defines noise indicators, noise limit values and methods for measuring noise, explains individual sources of noise and provides guidelines for the development of strategic noise maps, action noise protection plans through measures and conditions of protection, as well as rules for public information on noise and surveillance.

A number of by-laws have been adopted enabling the implementation of this Law, namely:

- Regulation on Noise Indicators, Limit Values, Methods for Evaluating Noise Indicators, Annoyance and Harmful Effects of Environmental Noise and on Human Health, and the Types and Methods of Collecting the Data Required for their Evaluation (Official Gazette of the RS, No. 75 / 2010),

- Rulebook on the Methodology for Determining Acoustic Zones ("RS Official Gazette", No. 72/2010),

- Ordinance on the Content and Methods of Drafting Strategic Noise Maps and how They are to be Presented to the Public ("RS Official Gazette", No. 80/2010),

- Rulebook on the Methodology for Action-plan Development (Official Gazette of the RS, No. 72/2010),

- Rulebook on the Methods of Noise Measurement, Content and Scope of Noise Measurement Reports (Official Gazette of RS, No. 72/2010),

- Rulebook on the Conditions to be Fulfilled by a Professional Organisation for Noise Measurement, and Documentation to be Submitted with the Application for Acquiring the Authorisation for Noise Measurement ("RS Official Gazette", No. 72/2010),

- Rulebook on Sound Level Meters (“RS Official Gazette”, No. 39/2014). 


\section{Acoustic zoning}

Acoustic zoning is the process of determining and prescribing a unique limit value for noise indicators for entire surfaces of different areas according to their purpose. The local self-government unit determines the acoustic zones in the settlement, as well as the limit values of noise indicators in those zones (day and night), expressed in decibels, according to the construction state, the way of land use and the planned purposes of the area, i.e. based on the reference maps of the spatial plans (Bing, Popp, 2011).

\section{Strategic noise maps}

A strategic noise map is a map made up of a set of data on existing noise levels in a particular area and it is used to estimate the total noise exposure of a particular area coming from different noise sources or to predict the total noise in an area. The development of strategic noise maps means the presentation of data on existing or estimated noise levels - including exceedances of prescribed limit values - the number of people exposed to noise in an area or the number of households exposed to certain values of noise indicators in a particular area. The law stipulates that strategic noise maps are compulsory for agglomerations with more than 100,000 inhabitants, for major roads with an average annual traffic flow of more than 3,000,000 vehicles, for major railways with an average annual traffic flow of more than 30,000 trains and for major airports.

In addition to the fact that it is legally required to produce strategic noise maps, this is also the most effective instrument for managing noise in the urban area, as it is a necessary prerequisite for developing action plans and defining effective and economically justifiable noise reduction measures.

In addition, detailed noise maps that analyze all noise sources and noise values on all facades of all dwellings (from the most exposed to the quiet facades) can be made. The results of these maps provide information for the sizing of sound insulation on facades, as well as for the selection of windows, ventilation ducts, installation pipes, etc., which is extremely important for the reconstruction of buildings (Bing, Popp, 2011).

Strategic noise maps, which need to be revised at least every five years, use the basis for the development of environmental noise action plans and as a means of informing the public about the level of environmental noise and its harmful effects. 


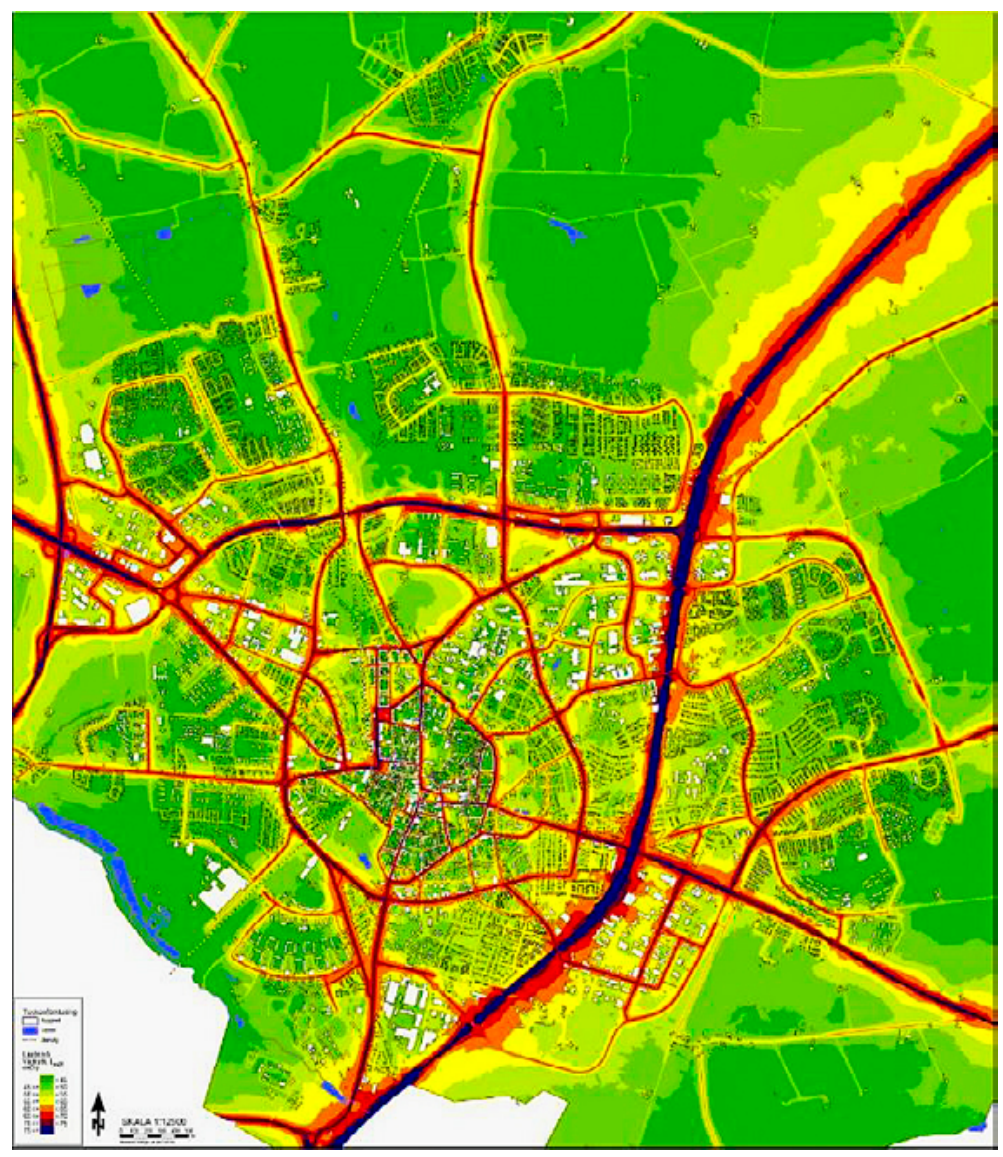

Figure 2. Noise map for the city of Lund

Source: Lunds kommuns åtgärdsprogram mot buller 2014-2018.

\section{ENVIRONMENTAL NOISE ACTION PLANS}

Environmental noise action plans are actually plans containing measures for the protection of noise and its effects in the environment, as well as measures for noise reduction in the event of exceeding limit values. An Environmental Noise Action Plan is developed for areas where limit values are exceeded, based on a strategic noise map for the same area. For the purpose of the development of action plans, conflicting noise maps are drawn up, which show the difference between the existing or predicted noise status and the threshold values of the noise indicators. A conflicting noise map is made on the basis of a strategic noise map, by the method of calculation, whereby noise limit values are subtracted from the level of the existing or predicted noise state (Bing, Popp, 2011).

The bases for the development of noise protection action plans are environmental noise protection measures (space planning, traffic planning, technical measures on noise sources, selection of noise sources with lower noise emission values, sound insu- 
lation, noise propagation measures, application of legislation and other regulations), assessment of the cost and effectiveness of noise reduction measures in a particular area, a list of legal and natural persons that influence noise exposure by their activity, and a timetable for the implementation of certain activities during the implementation of noise protection measures.

As the creation of strategic noise maps throughout the territory of the Republic of Serbia is currently entrusted to the Environmental Protection Agency, and since there is not enough institutional capacity for this task, there is a significant obstacle to the preparation of strategic noise maps - the Environmental Protection Agency has not produced any strategic noise maps so far. The plan of activities and sources of financing for the preparation of strategic noise maps is adopted by the Government at the proposal of the ministry responsible for the environment. Given that the Law establishes that strategic noise maps are used as a basis for the development of environmental noise action plans, but also as a means of informing the public about the level of environmental noise and its harmful effects, the lack of strategic noise maps has significant consequences on Noise management at the level of local self-government units, i.e. local self-government units, does not have sufficient instruments to use to adopt concrete measures that should be part of the noise protection action plans.

The most important instrument that local governments can unconditionally use to manage noise is acoustic zoning in their own territory. In acoustic zones, local self-government units may prohibit or restrict the use of noise sources, i.e. performing activities that cause noise above the prescribed limit values. The City of Belgrade made use of this instrument, and in 2011 the Regulation on Working Hours of Catering, Crafts and Trade Facilities in the City of Belgrade was adopted ("Official Gazette of the City of Belgrade", No. 2/2011 and 51/2011, "RS Official Gazette", No. 105/2012 - decision of the US, and Official Gazette of the City of Belgrade, No. 31/2013 - other decision). In addition, in April 2014, the City of Belgrade issued a Decision establishing the Program for the Use of Budget Funds for Environmental Protection of the City of Belgrade for the period from January to June 2014 (Official Gazette of the City of Belgrade, No. 37/2014), which envisages an acoustic zoning project for a part of the central zone of the City of Belgrade (parts of the municipalities of Stari grad, Savski Venac, Palilula, Vracar, Zemun and New Belgrade). It is pointed out that this project represents the first phase in the process of acoustic zoning of the City of Belgrade, since the zoning of the city's territory will be carried out in phases over the coming years, according to the appropriate plans and available financial means for this purpose. The result of the project will be a map with presented acoustic zones.

\section{NOISE PROTECTION MEASURES}

Noise protection is implemented in various ways. When it comes to the noise of production plants, space damping is the most commonly used as well as coating of noisy machines. Traffic barriers are the most commonly used sound barriers. Noise protection measures can be divided into: 
- Technical,

- Medical and

- Socio-legal.

\section{Technical measures for noise protection}

The protection in the sound path and in the case of outdoor sound sources shall be implemented using the following protection measures:

1. The noise source should be positioned as far as possible from the place where the sound is received. The intensity of the sound is inversely proportional to the square of the distance at point sources and the distance at cylindrical ones. Flat waves spread the most, but they also attenuate with distance according to exponential law.

2. The acoustic shelters should be applied, which can be divided into:

- Natural (hills, forests, parks),

- Artificial (built for this purpose), in which most of the sound energy is repelled by solid barriers, while porous barriers absorb sound well.

3. Avoiding harmful reflection - sound is most often reflected by multi-story facades and other concrete structures;

4. When designing, care shall be taken to ensure that noise-free rooms (bedrooms etc.) are on the quiet side of the building or in the central part of the building;

5. Application of sound insulation in the construction of windows and doors (double glazed windows are both good thermal and sound insulation, PVC joinery, airtight sealing of windows and doors etc.).

Indoor sound sources are protected using the following protection measures:

1. Placing the sound sources in the lowest part of the building, thereby allowing the ground to absorb sound;

2. Grouping and separating noisy from quiet rooms within one facility. Bedrooms are grouped to one side of the building, away from the elevator area;

3. Prevention of noise transmission through installations within the facility. Soundproofing of water and heating pipes through which mechanical waves can be transmitted is carried out. Insulating materials absorb sound and are chosen to be non-flammable or thermally resistant;

4. Selection of building elements for walls and floor structures;

5. The closure of sound sources into chambers whose construction is separate from the construction of the building. Typically, the engine lift compartment closes into a soundproofed chamber;

6. Increase in absorption. This is achieved by installing sound-absorbing materials, and it is also essential in the construction industry to be non-flammable.

Personal noise protection products are designed to reduce the noise level below 85 $\mathrm{dB}$, while allowing the transmission of the most important speech frequencies, to minimize interference with the person's work and to not cause side effects such as discomfort, pain, itching, allergic and irritant reactions. They are divided into 
1. Occlusal - intended for the external ear canal (plugs or antiphons), and

2. Obturation - which rest on the head area around the ear (safety helmets).

This includes protective suits, which are used when it is necessary to protect all organs of the human body from intense sound. They are made of textile materials with good protective properties, i.e. they absorb sound waves at all frequencies and have to meet other requirements such as comfort during operation and non-flammability (Poparić, 2011).

Organizational protection measures and rationalization of operating modes imply that when working in a noisy environment, a break of $10 \mathrm{~min}$ is made in a room insulated from noise every two hours. Also, if possible, work groups are organized so that they have two hours of work followed by two hours of break etc. in the work space exposed to noise (Poparić, 2011).

\section{Medical protection measures}

Medical noise protection measures are measures of regular health control, i.e. regular examinations of persons exposed to increased levels of noise in the workplace and they are implemented in an organized manner by the occupational health service.

Medical care measures can be divided into the following:

1. Professional orientation and selection This measure aims to identify noise-sensitive individuals and direct them to other occupations.

2. Preventive health examinations

- Preliminary examinations - when selecting candidates to work in a noisy environment, their possible individual hypersensitivity to noise should be examined and tests such as hearing fatigue tests and audiograms should be performed;

- Periodic examinations - aim to monitor hearing status; hearing control for workers exposed to noise should be performed at intervals not exceeding 6 months; for workers who have just started working these examinations should be performed on a daily basis;

- Extraordinary examinations - performed after exposure to high-intensity noise or after hearing ailments that may contribute to hearing loss (Poparić, 2011, Municipal Hygiene).

3. Identifying high-risk jobs

Jobs where noise exceeds the $85 \mathrm{~dB}$ level are jobs with special working conditions. In such workplaces, if technical and personal protective equipment cannot reduce the noise level below $85 \mathrm{~dB}$, the exposure time will be reduced.

4. Health awareness and education

This measure is aimed at the importance and necessity of wearing personal protective equipment and their regular and proper use. The worker should be introduced to the additional adverse effects of out-of-work noise, as well as to the possibility of recovery of temporary hearing loss (Poparić, 2011). 


\section{Socio-legal measures of protection}

Socio-legal protection measures are measures adopted at the national level in the form of norms, standards, rules and regulations on the permissible noise level and exposure time for a given noise level. There are a number of regulations governing the noise problem, prescribing the permissible noise level and setting criteria and standards for assessing the harmful effects of noise. The regulations to be adopted apply specifically to construction, traffic, industry, and there are also regulations on permitted levels of communal noise.

The Rulebook defines the standards for noise protection, methods and conditions for measuring and analyzing noise:

- A limit of $85 \mathrm{~dB}$ has been set in order to protect hearing from noise damage,

- In most countries, the maximum noise level for up to eight hours is up to $90 \mathrm{~dB}$,

- For noise below $350 \mathrm{~Hz}$ the upper limit is $100 \mathrm{~dB}$, and for noise of about $4000 \mathrm{~Hz}$ the upper limit is $80 \mathrm{~dB}$,

- If there is a need for voice communication at a distance of $4 \mathrm{~m}$, the permitted level is $50 \mathrm{~dB}$,

- If the noise is above $95 \mathrm{~dB}$, the allowed exposure time is 4 hours, and for a noise of $115 \mathrm{~dB}$ the exposure time is 15 minutes.

Table 2. International (OSHA) standard for continuous daily noise

\begin{tabular}{|c|c|}
\hline Noise level & Maximum allowed exposure \\
\hline $90 \mathrm{~dB}$ & 8 hours \\
\hline $92 \mathrm{~dB}$ & 6 hours \\
\hline $95 \mathrm{~dB}$ & 4 hours \\
\hline $97 \mathrm{~dB}$ & 3 hours \\
\hline $100 \mathrm{~dB}$ & 2 hours \\
\hline $102 \mathrm{~dB}$ & 1,5 hours \\
\hline $105 \mathrm{~dB}$ & 1 hour \\
\hline $110 \mathrm{~dB}$ & 30 minutes \\
\hline $115 \mathrm{~dB}$ & 15 minutes \\
\hline
\end{tabular}

Source: https://www.osha.gov/

The preceding table shows (according to USA OSHA - Occupational Safety \& Health Administration) how many hours a hearing impaired person can spend in a noisy environment to avoid hearing damage. For the people with already impaired hearing, the maximum noise level for 8 hours is $85 \mathrm{~dB}$ (Poparić, 2011). 


\section{CONCLUSION}

Today's society is increasingly concerned about noise protection, which is a type of environmental pollution. Accurate noise measurement, although necessary, is often very expensive, especially if one wants to measure noise at multiple points in an area at a time. Therefore, many cities do not approach this issue with sufficient commitment.

Protection measures can be taken in three ways: by preventing noise at the source where it is formed, by reducing noise by placing the source at a greater distance (by crossing the path of noise transfer), and by using personal noise shields.

Given the small potential for reducing the number of vehicles in traffic and the frequency of use of vehicles, preventive measures can be implemented to protect human health. In order to reduce communal noise, it is necessary to constantly monitor the level of communal noise in the environment, to ensure proper urban planning of cities, to control the noise level emitted by motor vehicles during their technical inspection, to constantly monitor the level of communal noise emitted by motor vehicles, to plan the street network with automatic control more effectively traffic and synchronization of traffic lights, green the public areas, provide easy accessibility to parking spaces, develop action plans to reduce noise levels in cities, the main objective of which is to reduce environmental noise to reduce the number of people disturbed by noise.

Given the small potential for reducing the number of vehicles in traffic and the frequency of use of vehicles, preventive measures can be implemented to protect human health. In order to reduce communal noise, it is necessary to constantly monitor the level of communal noise in the environment, to ensure proper urban planning of cities, to control the noise level emitted by motor vehicles during technical inspection, to constantly monitor the level of communal noise emitted by motor vehicles, to plan the street network with automatic control and synchronization of traffic lights more effectively, perform afforestation of public areas, provide easy accessibility to parking spaces, develop action plans to reduce noise levels in cities, the main objective of which is to reduce environmental noise to reduce the number of people disturbed by noise.

\section{ACKNOWLEDGEMENTS}

The authors would like to express their sincere thanks to the Ministry of Education, Science and Technological Development of the Republic of Serbia (Project No. 176020), and the Provincial Secretariat for Higher Education and Scientific Research of the Vojvodina Province, Republic of Serbia (Project No. 142-451-2123/2019-03), for their financial support. 


\section{REFERENCES}

Allen, R.W., Davies, H., Cohen, M.A., Mallach, G., Kaufman, J.D. and Adar, S.D. (2009). The spatial relationship between traffic-generated air pollution and noise in 2 US cities, Environmental Research, 109, pp. 334-342.

Ausejo, M., Recuero, M., Asensio, C., Pavon, I. and Lopez, J.M. (2010). Study of precision, deviations and uncertainty in the design of the strategic noise map of the macrocenter of the city of Buenos Aires, Argentina, Environmental Modeling and Assessment, 15, pp. 125-135.

Belojević, G., Paunović, K., Jakovljević, B., Stojanov, V., Ilić, J., Slepčević, V. and SarićTanasković, M. (2011). Cardiovascular effects of environmental noise: research in Serbia, Noise Health, 13(52), pp. 217-220.

Bing, M., Popp, C. (2011). Noise action planning in agglomerations, Reduction potentials based on the example of Hamburg, Federal Environment Agency (Umweltbundesamt), Dessau-Roßlau.

Brainard, J.S., Jones, A.P., Bateman, I.J. and Lovett, A.A. (2004). Exposure to environmental urban noise pollution in Birmingham, UK, Urban Studies, 41(13), pp. 2581-2600.

Đerčan, B. (2019). Istraživanje buke u urbanoj sredini Novog Sada sa predlozima urbanističkih mera za njeno smanjenje, Zbornik radova Fakulteta tehničkih nauka, 34 (2), 397-400.

Đerčan, B., Bubalo-Živković, M., Lukić, T., Pantelić, M., Marković, S.B. (2015). Road Traffic Noise Exposure in the City of Novi Sad: Trend Analysis and Possible Solutions, Polish Journal of Environmental Studies, 24(3), 977-986.

Đerčan, B., Radaković, M., Ostojić, M., Mirković, M., Obrenov, S., Vozar, J. (2017). Urban hierarchy in Serbia, Zbornik radova Departmana za geografiju, turizam i hotelijerstvo, 46(1), 11-23.

Ecological Bulletin (2004). City Environmental Protection Authority, Novi Sad.

European Commission (2002). Directive 2002/49/EC of the European Parliament and of the Council of 25 June 2002 relating to the assessment and management of environmental noise. Official J. Eur. Commun. L189, 12-25.

Gan, W. Q., McLean, K., Brauer, M., Chiarello, S. A., Davies, H. W. (2012). Modeling population exposure to community noise and air pollution in a large metropolitan area, Environmental Research, 116, pp. 11-16.

Geurs, K.T. and Wee, B.V. (2006). Ex-post evaluation of thirty years of compact urban development in the Netherlands, Urban Studies, 43(1), pp. 139-160.

Jaafreh, O. A., Nagy, I. (2018). The environmental challenges, problems, and management: a case study of Jordan, Zbornik radova Departmana za geografiju, turizam i hotelijerstvo, 47(1), 53-70.

Jovašević, D. (2005). Zaštita životne sredine, Beograd: Službeni list SCG.

Kristoforović-Ilić, M., Radovanović, M., Vajagić, L., Jevtić, Z., Folić, R., Krnjetin, S. and Obrknežev, R. (1998). Komunalna higijena, Novi Sad: Univerzitet u Novom Sadu, Medicinski fakultet, Prometej.

$\mathrm{Li}, \mathrm{B}$. and Tao, S. (2004). Influence of expanding ring roads on traffic noise in Beijing City, Applied Acoustics, 65, 243-249. 
Li, B., Tao, S. and Dawson, R.W. (2002). Evaluation and analysis of traffic noise from the main urban roads in Beijing, Applied Acoustics, 63, pp. 1137-1142.

Lunds kommuns åtgärdsprogram mot buller 2014-2018.

Noise reduction plan for Berlin - Action plan, (2008). Senatsverwaltung für Gesundheit, Umwelt und Verbraucherschutz Abt. III Umweltpolitik, Referat Immissionsschutz, Berlin.

Official Gazette of the Republic of Serbia No. 72/2010, Rulebook on the Conditions to be Fulfilled by a Professional Organisation for Noise Measurement, and Documentation to be Submitted with the Application for Acquiring the Authorisation for Noise Measurement.

Official Gazette of the Republic of Serbia, No. 80/2010, Ordinance on the Content and Methods of Drafting Strategic Noise Maps and how They are to be Presented to the Public.

Official Gazette of the Republic of Serbia, No. 36/2009, 88/2010, Law on Protection against Environmental Noise.

Official Gazette of the Republic of Serbia, No. 39/2014, Rulebook on Sound Level Meters.

Official Gazette of the Republic of Serbia, No. 72/2010, Rulebook on the Methodology for Determining Acoustic Zones.

Official Gazette of the Republic of Serbia, No. 72/2010, Rulebook on the Methodology for Action-plan Development.

Official Gazette of the Republic of Serbia, No. 72/2010, Rulebook on the Methods of Noise Measurement, Content and Scope of Noise Measurement Reports.

Official Gazette of the Republic of Serbia, No. 75 / 2010, Regulation on Noise Indicators, Limit Values, Methods for Evaluating Noise Indicators, Annoyance and Harmful Effects of Environmental Noise and on Human Health, and the Types and Methods of Collecting the Data Required for their Evaluation.

Poparić, G. B. (2011). Monitoring buke (skripta), Univerzitet u Beogradu, Geografski fakultet Fizički fakultet.

Ross, Z., Kheirbek, I., Clougherty, J.E., Ito, K., Matte, T., Markowitz, S. and Eisl, H. (2011). Noise, air pollutants and traffic: Continuous measurement and correlation at a high-traffic location in New York City, Environmental Research, 111, pp. 1054-1063.

United Nations (2019). World Population Prospects, Volume II: Demographic Profiles, Department of Economic and Social Affairs, Population Division, New York: United Nations.

United States Department of Labor, Occupational Safety and Health Administration, Occupational Noise Exposure, available at https://www.osha.gov/

World Health Organization (2011). Burden of disease from environmental noise - Quantification of healthy life years lost in Europe, WHO European Centre for Environment and Health. Bonn Office. Available: http://www.who.int/quantifying ehimpacts/ publications/e94888.pdf (accessed 12.08.2019.).

World Health Organization (2012). Environmental health inequalities in Europe, WHO European Centre for Environment and Health. Bonn Office. http://www.euro.who. int/ data/assets/pdf file/0010/157969/e96194.pdf (accessed 12.08.2019.). 